DOI: 10.20472/EFC.2021.015.011

\author{
MONICA KOLESOVA \\ Ural Federal University, Russian Federation
}

ANNA GAINETDINOVA

Ural Federal University, Russian Federation

OLEG MARIEV

Ural Federal University, Russian Federation

\title{
PERMANENT INCOME HYPOTHESES TESTING: EVIDENCE FROM RUSSIA
}

\begin{abstract}
:
Consumption and income nexus is determined either by permanent income hypothesis or excess sensitivity hypothesis. Our study is based on the study Campbell and Mankiw (1989), who conducted analysis for the US. In our study, we test the aforementioned hypotheses in the context of Russia using quarterly data. Afterwards, we check whether sensitivity of consumption to disposable income depends on economic development of a country. Therefore, we test permanent and excess sensitivity hypotheses in the context of developed and developing countries. By employing Campbell-Mankiw model we use two-stage least squares method using instrumental variables. The results demonstrate that the best instruments for Russia are lags in income, oil price and interest rate. All Russian agents consume their temporary income, which is an indicator of a risky financial environment. When considering the groups of developed and developing countries, the results demonstrate that developing countries with relatively better financial system comprise two groups of agents: a group consuming permanent income and a group consuming temporary income. At the same time, in some developed countries having less stable financial system, all agents consume their temporary income.
\end{abstract}

\section{Keywords:}

Excess sensitivity, consumption, permanent income hypothesis, random walk hypothesis, Friedman function

JEL Classification: E24, 015 


\section{Introduction}

Consumption and income nexus is determined either by permanent income hypothesis or excess sensitivity hypothesis. Permanent income hypothesis was introduced by Milton Friedman (1957) and extended by Hall (1978). Studies of Dajuan et al (2004), Flavin (1981), Campbell and Mankiw (1989) and Arefieva (2009) test permanent income hypothesis or excess sensitivity hypothesis on the example of different countries. Our study is based on Campbell and Mankiw (1989) who reveal that half of agents in USA behaves according to permanent income hypothesis, while another half behaves according to excess sensitivity hypothesis. We conduct our study in the context of Russia, incorporating the role of oil price since Russia is one of the largest oil exporters. Moreover, we investigate how sensitivity of consumption to disposable income varies at different stages of economic development by conducting analysis for groups of developed and developing countries. We compare the result obtained for Russia with the result obtained for a different transitional economy (Czech Republic). In our study we employ Campbell-Mankiw model and apply two-stage least squares method using instrumental variables. We reveal that all Russian agents consume their temporary income, which is an indicator of unstable financial system. Our result is in line with Arefieva (2009). Analysis for developed countries, developing countries and countries with transitional economy demonstrates that sensitivity degree does not entirely depend on the level of economic development. For example, Korea, USA and Chile have two groups of agents including those who consume permanent income and those who consume temporary income. Similar, in France, Czech Republic and Russia all agents consume their temporary income, though countries are at the different stage of economic development. Therefore, we argue that sensitivity of consumption can be induced by liquidity constraints and stock market investment risks. In this sense, some developing countries may have less risky financial environment as compared to some developed countries.

\section{$2 \quad$ Literature review}

The main factor, which drives changes in consumption, is income. According to the permanent income hypothesis (1) introduced by Milton Friedman (1957), consumption is mainly determined by permanent income, while temporary income is used for savings.

$$
C=\alpha Y^{p}
$$

Where $\mathrm{C}$ is consumption,

$\alpha$ is a parameter (from 0 to 1 ),

$Y^{p}$ is permanent income.

Friedman function shows that permanent income accounts for the largest part of consumption. When temporary income is less than permanent, a consumer would prefer to smooth out consumption by spending part of savings or borrowing money. The permanent income hypothesis implies that the consumer smoothes out consumption throughout his life. Permanent income hypothesis states that consumption follows a random walk process. The random walk hypothesis assumes that the change in consumption between two periods is due to income change in future period. At the same time, this change does not depend on income in past periods. 
Hall (1978) investigates the influence of disposable income on consumption by using quarterly USA data from 1948 to 1977 . The results demonstrate that income in past periods does not influence current consumption confirming the theory of random walk. Dajuan et al (2004) obtained similar result by applying the permanent income hypothesis to 48 US states. Dajuan et al (2004) argue that the permanent income hypothesis is a suitable model to describe the response of consumption to changes in income at the level of USA states.

Flavin (1981) obtains the result which contradicts the findings of Hall (1978) and Dajuan et al (2004). The study measures the response of consumption to changing expectations regarding future income. Flavin (1981) reveals that consumption has high degree of sensitivity to previous changes in income, which controverts the permanent income hypothesis. This result is called excess sensitivity hypothesis.

The permanent income hypothesis assumes that all agents consume their permanent income, and the excess sensitivity hypothesis states that that all agents consume temporary income. By combining the ideas of these hypotheses, Campbell and Mankiw (1989) propose that there are two groups of consumers, where the first group consumes its permanent income, and the second spends temporary income.

Campbell and Mankiw's model is based on a permanent income model in which consumption follows a random walk process. The study solves the problem of a rational foresighted representative agent and as a result obtains the Euler equation (2):

$$
E_{t}\left(u^{\prime}\left(C_{t+1}\right)\right)=\frac{1+p}{1+r} u^{v}\left(C_{t}\right) \text {. }
$$

Where $r$ stands for interest rate,

$\rho$ indicates the coefficient of intertemporal consumer preferences,

$C_{t}, C_{t+1}$ represent consumption in period $(\mathrm{t})$ and $(\mathrm{t}+1)$ respectively,

$E_{t}$ is operator of rational expectations.

Assuming linear marginal utility (the principle of equivalence to the deterministic case) and equality of the interest rate and the rate of intertemporal preferences, Campbell and Mankiw (1989) derive the following equation:

$$
\Delta C=\varepsilon_{t}
$$

where $\varepsilon_{t}$ is a random shock.

Moreover, the study of Campbell and Mankiw (1989) considers generalized model: $\lambda$ income belongs to the first group of agents consuming temporary income, whereas $(1-\lambda)$ income belongs to "foresighted" agents. Equation (4) divides the entire income $Y_{t}$ at each moment of time into the sum of the incomes of two groups of households as following:

$$
Y_{t}=Y_{1 t}+Y_{2 t}
$$

where $Y_{1 t}=\lambda Y_{t}$ and $Y_{2 t}=(1-\lambda) Y_{t}, \lambda$ indicates the share of the total income belonging to the agents of the first group.

Since agents from the first group consume their temporary income, the equation of their consumption (5) is represented as:

$$
\Delta C_{1}=\Delta Y_{1 t}=\lambda \Delta Y_{t}
$$

The behavior of the second group of consumers follows the hypothesis of permanent income, therefore, their consumption is a process of a random walk, which is represented in equation (6):

$$
\Delta C_{2 t}=(1-\lambda) \varepsilon_{t}
$$

Thus, the consumers form their consumption as following (7):

$$
\Delta C_{t}=\lambda \Delta Y_{t}+(1-\lambda) \varepsilon_{t}
$$


where $\lambda$ is the share of agents consuming their temporary income;

$1-\lambda$ indicates the share of agents consuming permanent income;

$\varepsilon_{t}$ signifies random shock.

Thus, Campbell and Mankiw (1989) in their study document that the excess sensitivity coefficient is approximately equal to 0.5 indicating that half of the agents in the United States consumes their temporary income, whereas another half consumes permanent.

Arefieva (2009) tests permanent income hypothesis on Russian quarterly data from 1995 to 2008. The results demonstrate that the share of agents consuming their temporary income is close to one contradicting the hypothesis of permanent income.

\section{Data}

We conduct our study for Russia for the period of $2014-2020$ by using quarterly data. In order to check whether the coefficient of excess sensitivity depends on the economic development of the country, we conduct analysis for developed countries, developing countries and countries with transitional economies by using yearly data. Sample of developed countries includes Korea, France, United States, and sample of developing countries involves Turkey and Chile. Czech Republic is taken as transitional economy. The data description of the aforementioned countries is represented in table 1.

\section{Table 1 - Data description}

\begin{tabular}{|l|l|l|l|}
\hline Name & Description & Source of Russian data & $\begin{array}{l}\text { Source of data for } \\
\text { groups of countries }\end{array}$ \\
\hline Consumption & Real consumer spending & $\begin{array}{l}\text { Federal State Statistics } \\
\text { Service-Rosstat }\end{array}$ & Knoema \\
\hline Income & Real disposable income & $\begin{array}{l}\text { Federal State Statistics } \\
\text { Service-Rosstat }\end{array}$ & $\begin{array}{l}\text { OECD-Organization for } \\
\text { Economic Cooperation } \\
\text { and Development }\end{array}$ \\
\hline $\begin{array}{l}\text { Stock market } \\
\text { index }\end{array}$ & $\begin{array}{l}\text { Stock market index of } \\
\text { relative country }\end{array}$ & RTS website & $\begin{array}{l}\text { Financial } \\
\text { Investing.com }\end{array}$ \\
\hline Interest rate & $\begin{array}{l}\text { Nominal deposits interest } \\
\text { rates }\end{array}$ & Bank of Russia & Knoema \\
\hline Oil price & Brent crude oil price & Bloomberg website & \\
\hline
\end{tabular}

For each country we choose the main indicator of stock market. List of stock market indexes chosen for countries is represented in table 2

Table 1 - Stock market indexes used in analysis

\begin{tabular}{|l|l|}
\hline Stock market index & Country \\
\hline RTS index & Russia \\
\hline PX Index & Czech Republic \\
\hline SPCLXIGPA & Chile \\
\hline
\end{tabular}




\begin{tabular}{|l|l|}
\hline XU100.IS & Turkey \\
\hline KOSPI & Korea \\
\hline CAC 40 (FCHI) & France \\
\hline Nasdaq 100 (NDX) & USA \\
\hline
\end{tabular}

We choose these variables, basing on the study of Campbell and Mankiw (1989). By doing so, we check the results obtained by Campbell and Mankiw (1989) in the context of Russia. Moreover, we extend the investigation of Arefieva (2009) by conducting study with updated data. We include oil price variable for Russia, since Russia is one of the largest oil exporter and highly dependent on oil.

We obtain data due to its maximum availability. Therefore, periods for analysis vary from country to country, e.g. Russia (2014-2020), Czech Republic (2000-2020), Chile (2000-2020), Turkey (2000 - 2020), Korea (2000 - 2020), France (1995-2017), USA (1995 - 2020).Model 3 has been extended to include lags in cash flow, debt, and free cash. We suggest that capital investment response to these factors may be delayed.

\section{$4 \quad$ Methodology}

Since consumption can be highly correlated with error term, we use two-stage least squares method using a vector of instrumental variables. The first step is equation (8) and the second step is equation (9):

$$
\begin{aligned}
& \Delta \mathrm{c}_{\mathrm{y}}=\mu+\lambda \Delta \mathrm{y}_{\mathrm{t}} \\
& \Delta \mathrm{y}_{\mathrm{t}}=\alpha \mathrm{X}_{\mathrm{t}}+\eta_{\mathrm{yt}}
\end{aligned}
$$

where $\Delta \mathrm{C}_{\mathrm{y}}$ indicates change in consumption;

$\Delta y_{\mathrm{t}}$ stands for change in income;

$\eta_{y t}$ is random shocks in income equation;

$X_{t}$ represents vector of instrumental variables.

In order to consider the influence of previous periods, we also take lags of income and consumption variables as instrumental variables. When applying two-stage least squares method, we test a hypothesis (10) for weak instrument:

$$
\alpha=0
$$

If hypothesis (10) is not rejected, we conclude that instrument is weak and cannot be used for two-stage least squares method. In case when hypothesis is rejected, instrument is reliable. The excess sensitivity coefficient $\lambda$ is determined from the equations for consumption (8) and income (9). In our study, we test hypothesis (11) and (12).

$$
\begin{aligned}
& \lambda=0 \\
& \lambda>0
\end{aligned}
$$

If null hypothesis (10) is not rejected, consumption is characterized by random walk, indicating that permanent income hypothesis is confirmed. If hypothesis (11) is accepted, agents consume their temporary income, implying that their consumption is characterized by excess sensitivity. 


\section{$5 \quad$ Results and Discussion}

Table 3 represents regression results for Russia. The first column indicates the number of regression. The second column of table 3 indicates instrumental variable used in the regression, the third column contains R-squared and $p$-values for regressions. The fourth column contains coefficients of $\lambda$ obtained by the method of instrumental variables, and the fifth column reflects $p$ value for $\lambda$ coefficient. Finally, the sixth column reports significance of the instrument.

First, we observe the influence of income in previous periods. The results demonstrate that fifth and sixth lags are weak instruments, therefore we cannot rely on $\lambda$ coefficient in the first and second regressions. The fourth, third and second lags are strong instruments. Hence, we can use them to assess sensitivity. Third and second lags has significant sensitivity coefficient. Since $\square$ is positive and more than one, we conclude that consumers in Russia follow excess sensitivity of consumption.

Second, we observe the impact of consumption in previous periods (regressions 6-9). The second and third lag are weak instruments. The fifth and sixth lags are significant, therefore we can use them to assess excess sensitivity. The coefficient $\lambda$ is insignificant for fifth lag, however, it is significant for sixth lag. In general, lags of consumption are less reliable instrument than lags of income. The results for sixth regression demonstrate confirm the hypothesis that consumers spend their temporary income for consumption. The hypothesis about permanent income is not confirmed.

Third, we consider the change in oil prices as an instrumental variable for our regression 10 . The result demonstrates that oil price is a strong instrument, indicating that we can use it to assess sensitivity. The coefficient of sensitivity is significant at all levels of significance and equals to 1.368. Thus, we document that regression with oil price as instrumental variable accepts the hypothesis of excess sensitivity.

Fourth, we consider financial variables as instruments. In regression 11 we take interest rate is used as an instrument. By conducting weak instrument test, we conclude that instrument is strong. Coefficient of sensitivity is significant and equals to 1.454. Therefore, in this regression the hypothesis of excess sensitivity is accepted indicating that in Russia agents consume their temporary income. In regression 12 we employ RTS index, which was taken as a proxy for stock prices. However, by applying weak instrument test we observe that this variable is not reliable in determining the coefficient of sensitivity.

Table 3 - Results of permanent income and excess sensitivity hypothesis testing for Russia (1Q2014- 4Q2020)

\begin{tabular}{|c|c|c|c|c|c|}
\hline № & Instruments & $\begin{array}{c}\text { R-squared, } \\
\text { p-value }\end{array}$ & $\lambda$ (err) $^{2}$ & p-value for $\lambda$ & $\begin{array}{c}\text { Weak } \\
\text { instrument }_{\text {test }}{ }^{3}\end{array}$ \\
\hline $\mathbf{1}$ & Income $(6$ & $0.799(\mathbf{0 . 0 0 0})$ & 4.5048 & $\mathbf{0 . 0 8 2}$ & 0.636 \\
\hline
\end{tabular}

\footnotetext{
${ }^{1} \mathrm{R}$-squared for regression, $\mathrm{p}$-value is given in brackets

2 Sensitivity coefficient, standard errors are given in brackets

${ }^{3}$ Reports significance of instrument in equation (9)
} 


\begin{tabular}{|c|c|c|c|c|c|}
\hline & lag) & & $(2.588)$ & & \\
\hline 2 & $\begin{array}{c}\text { Income (5 } \\
\text { lag) }\end{array}$ & $\begin{array}{c}0.585 \\
(0.0194)\end{array}$ & $\begin{array}{c}0.40516 \\
(1.013)\end{array}$ & 0.689 & 0.109 \\
\hline 3 & $\begin{array}{l}\text { Income (4 } \\
\text { lag) }\end{array}$ & $\begin{array}{l}0.7235 \\
(\mathbf{0 . 0 0 0 )}\end{array}$ & $\begin{array}{c}1.0727 \\
(0.7103)\end{array}$ & 0.131 & 0.069 \\
\hline 4 & $\begin{array}{c}\text { Income (3 } \\
\text { lag) }\end{array}$ & $0.854(\mathbf{0 . 0 0 0 )}$ & $\begin{array}{l}2.0684 \\
(0.4634)\end{array}$ & 0.000 & 0.048 \\
\hline 5 & $\begin{array}{l}\text { Income (2 } \\
\text { lag) }\end{array}$ & $0.766(0.000)$ & $\begin{array}{c}1.3319 \\
(0.2617)\end{array}$ & 0.000 & 0.001 \\
\hline 6 & $\begin{array}{l}\text { Consumption } \\
\text { (6 lag) }\end{array}$ & $\begin{array}{l}0.7358 \\
(0.000)\end{array}$ & $\begin{array}{c}1.143 \\
(0.5529)\end{array}$ & 0.039 & 0.030 \\
\hline 7 & $\begin{array}{l}\text { Consumption } \\
\text { (5 lag) }\end{array}$ & $0.557(\mathbf{0 . 0 3 2})$ & $\begin{array}{c}0.287 \\
(0.6947)\end{array}$ & 0.679 & 0.026 \\
\hline 8 & $\begin{array}{l}\text { Consumption } \\
\text { (3 lag) }\end{array}$ & $0.685(\mathbf{0 . 0 0 1 )}$ & $0.867(0.978)$ & 0.375 & 0.142 \\
\hline 9 & $\begin{array}{l}\text { Consumption } \\
\text { (2 lag) }\end{array}$ & $0.862(\mathbf{0 . 0 0 0 )}$ & $2.157(0.820)$ & 0.009 & 0.235 \\
\hline 10 & Oil price (log) & $0.772(\mathbf{0 . 0 0 0})$ & $1.368(0.427)$ & 0.001 & 0.013 \\
\hline 11 & Interest rate & $0.784(0.000)$ & $1.454(0.401)$ & 0.000 & 0.011 \\
\hline 12 & RTS index & $0.828(\mathbf{0 . 0 0 0 )}$ & $\begin{array}{c}1.801 \\
(0.7102)\end{array}$ & 0.011 & 0.136 \\
\hline
\end{tabular}

Source: Own estimations

Note: bold values indicate significance at $10 \%$ level

Afterward, we consider sensitivity estimators for developed countries, developing countries and country with transitional economy. For each country we have chosen best instrumental variables, which are represented in the table 4.

Table 4 - Results of permanent income and excess sensitivity hypothesis testing for developed and developing countries

\begin{tabular}{|c|c|c|c|c|c|}
\hline № & Country & Instrument & $\begin{array}{c}\mathbf{R}^{2}, \mathbf{p} \text {-value, } \\
\Delta \mathbf{C}^{1}\end{array}$ & $\lambda(\mathrm{err})^{2}$ & -value for $\lambda$ \\
\hline \multicolumn{3}{|c|}{ Developed countries } \\
\hline \multicolumn{3}{|c|}{}
\end{tabular}

\footnotetext{
${ }^{1} \mathrm{R}$-squared for regression, $\mathrm{p}$-value is given in brackets

${ }^{2}$ Sensitivity coefficient, standard errors are given in brackets
} 


\begin{tabular}{|c|c|c|c|c|c|}
\hline 1 & $\begin{array}{c}\text { Korea } \\
(2000-2020)\end{array}$ & Stock market index & $0.4284(\mathbf{0 . 0 0 1 8})$ & $0.5(0.182)$ & 0.006 \\
\hline 2 & $\begin{array}{c}\text { France } \\
(1995-2017)\end{array}$ & $\begin{array}{c}\text { Income (lag } 2-\operatorname{lag} 4) \\
\text { Consumption (lag } 2- \\
\text { lag 4) }\end{array}$ & $0.6604(0.000)$ & $1.55(0.584)$ & 0.008 \\
\hline 3 & $\begin{array}{c}\text { USA } \\
(1995-2020)\end{array}$ & Stock market index & $0.839(\mathbf{0 . 0 0 0})$ & $0.615(0.116)$ & 0.000 \\
\hline \multicolumn{6}{|c|}{ Transition economy } \\
\hline 4 & $\begin{array}{c}\text { Czech } \\
\text { Republic } \\
(2000-2020)\end{array}$ & $\begin{array}{c}\text { Income (lag } 2-\operatorname{lag} 4) \\
\text { Consumption (lag } 2- \\
\text { lag 4) }\end{array}$ & $0.7049(\mathbf{0 . 0 0 0})$ & $1.729(0.521)$ & 0.001 \\
\hline \multicolumn{6}{|c|}{ Developing countries } \\
\hline 5 & $\begin{array}{c}\text { Turkey } \\
(2000-2019)\end{array}$ & $\begin{array}{c}\text { Income (lag } 2-\operatorname{lag} 4) \\
\text { Consumption (lag } 2- \\
\text { lag 4) }\end{array}$ & $0.878(\mathbf{0 . 0 0 0})$ & $0.864(0.1435)$ & 0.000 \\
\hline 6 & $\begin{array}{c}\text { Chile } \\
(2000-2020)\end{array}$ & $\begin{array}{l}\text { Income (lag } 2-\operatorname{lag} 4) \\
\text { Consumption (lag } 2- \\
\text { lag 4) }\end{array}$ & $0.9995(\mathbf{0 . 0 6 3})$ & $0.669(0.287)$ & 0.007 \\
\hline
\end{tabular}

Source: Own estimations based on financial statements data

Note: bold values indicate significance at $10 \%$ level

Afterwards, we compare the results for Russia with the results for developed and developing countries, and another transitional economy - Czech Republic. For France we use 2-4 lags of income and consumption as instrumental variables since these instruments are not weak. Sensitivity coefficient are significantly positive, indicating that hypothesis of excess sensitivity is confirmed. Moreover, since sensitivity coefficient is high, all agents consume their temporary income. As for the US and Korea, we choose change in stock prices as instrumental variable since weak instrument test has shown significant result. Sensitivity coefficient is significant. Hence, consumption behavior in developed countries is characterized by excess sensitivity to disposable income. Moreover, sensitivity coefficient of Korea and USA is close to 0.5 indicating that in these countries consumers are divided on 2 groups of consumers as in the study of Campbell and Mankiw (1989). Approximately half of the population consumes their permanent income, whereas another half consumes temporary income.

For transition economy Czech Republic we use 2-4 lags of income and consumption as instrumental variables which are strong instruments. Sensitivity coefficient is significantly positive, indicating that hypothesis of excess sensitivity is confirmed. More specifically, generally consumption behavior corresponds to excess sensitivity hypothesis. 
When analyzing developing group of countries, we select 2-4 lags of income and consumption as instrumental variables. The results for Turkey show that sensitivity coefficient is significant and equals to 0.864 . The coefficient is close to one, therefore, the largest part of the population consume their temporary income, confirming excess sensitivity hypothesis. The results for Chile demonstrate that sensitivity coefficient is significant and equals to 0.669 , which is close to 0.5 . These findings are in line with Campbell and Mankiw (1989), indicating that half of agents consume their permanent income, and another part consumes their temporary income.

Thus, we can conclude that sensitivity degree of consumption to disposable income does not entirely depend on the level of economic development. For example, Korea, USA and Chile have two groups of agents including those who consume permanent income and those who consume temporary income. Similar, in France, Czech Republic and Russia all agents consume their temporary income, though France is developing country, whereas Czech Republic and Russia are transitional economy countries. We argue that such result can be connected with the fact that some developing countries may have relatively better financial system, inducing a part of agents to consume temporary income. Accordingly, developed countries can experience exogenous shocks, disrupting the stability of the financial system and inducing agents to spend their temporary income on consumption.

\section{Conclusion}

In our study, we introduce Campbell-Mankew model which is based on testing permanent income and excess sensitivity hypotheses by applying two-stage least squares method using instrumental variables. The main result obtained by Campbell and Mankew (1989) is division of all agents into 2 types: agents who consume their permanent income and agents who consume temporary income. In different studies the same instrumental variables provided different results. For example, in the study of Campbell and Mankew (1989), the best instrument is interest rate, and according to the study of Arefieva (2009), the best instrument is change in stock prices. Moreover, Arefieva (2009) documents that all Russian agents consume their temporary income. However, there is no recent study on testing permanent income hypothesis in Russia, what motivates us to conduct this study.

In order to test permanent income and excess sensitivity hypotheses in the context of Russia, we use updated quarterly data for the period of 2014-2020. In our study, the best instruments for Russia are lags in income, oil price and interest rate. Our empirical analysis follows CampbellMankew model. The findings are consistent with Arefieva (2009). All Russian agents still consume their temporary income, which is an indicator of unstable financial system. In order to check whether permanent income hypothesis holds at different stages of economic development, we conduct analysis for a group of developed countries, developing countries and countries in transition (Korea, France, Chile, USA, Czech Republic and Turkey). The results demonstrate that developing countries with relatively better financial system have two groups of agents: those who consume permanent income and a group consuming temporary income. At the same time, in some developed countries having less stable financial system, all agents consume their temporary income. Sensitivity of consumption can be induced by liquidity constraints and stock market investment risks. In this sense, some developing countries may have less risky financial environment as compared to some developed countries. 


\section{$7 \quad$ Acknowledgments}

Research was supported by the grant of the Russian Science Foundation № 19-18-00262 "Empirical modelling of balanced technological and socioeconomic development in the Russian regions".

\section{References}

1. Direct Test of the Permanent Income Hypothesis with an Application to the US States / Dejuan JP, Seater JJ, Wirjanto TS // Journal of Money. - 2004.

2. The Permanent Income Hypothesis / M. . Friedman // A theory of the consumption function. - 1957. - c. 20-37.

3. Permanent Income Hypothesis: Theory and Evidence // Journal of Political Economy. - 1978. №86(6). - c. 971-87.

4. The Adjustment of Consumption to Changing Expectations About Future Income / M.Flavin // Journal of Political Economy. - 1981. - c. 974-1009.

5. Consumption, Income and Interest Rates: Reinterpreting the Time Series Evidence / John Y. Campbell, N. Gregory Mankiw // NBER Macroeconomics Annual. - 1989. - c. 185 - 246.

6. Heterogeneous agents in the theory of consumption / A. Arefieva // Financial journal. -2009 . - c. 147-159. 